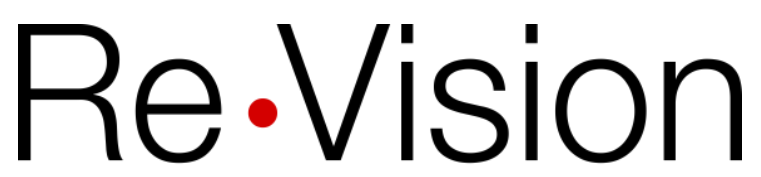

UNIVERSITY

The Centre for Art and Social Justice

\title{
Beyond "healthy eating" and
}

\section{"healthy weights": Harassment and the health curriculum in middle schools}

June Larkin

University of Toronto

Carla Rice

Trent University

This is an Accepted Manuscript of an article published by Elsevier in Body Image: An International Journal of Research in 2005, available online: https://doi.org/10.1016/j.bodyim.2005.07.001

This work is released under a Creative Commons Attribution Non-Commercial No Derivatives License.

\section{Recommended citation:}

Larkin, J., \& Rice, C. (2005). Beyond "healthy eating" and "healthy weights": Harassment and the health curriculum in middle schools. Body Image: An International Journal of Research, 2(3), 219-232. https:// doi.org/10.1016/j.bodyim.2005.07.001 


\section{Beyond "healthy eating" and "healthy weights": Harassment and the health curriculum in middle schools}

June Larkin and Carla Rice

\section{Abstract}

In this paper we use data from interviews conducted with grades 7 and 8 girls to explore connections between body-based harassment and girls' body modification practices. We discuss how the elementary health curricula fail to consider harassment and other cultural factors that influence the body modification practices and eating patterns of diverse girls. More specifically, we argue that the "healthy eating, healthy weights" approach of the grades 7 and 8 Ontario health curriculum has five limitations: (1) it sends contradictory messages; (2) it increases anxieties about body weight; (3) it ignores the multiple causes of eating problems; (4) it marginalizes issues most relevant to racialized girls; and (5) it ignores dilemmas associated with physical development. We conclude with suggestions for developing a curriculum on body dissatisfaction and eating disorders prevention that considers the various socio-cultural factors influencing the range of body monitoring and modifying practices taken up by girls.

\section{Keywords}

Body dissatisfaction; Harassment; Girls; Body modification; Prevention; Curriculum

\section{Introduction}


Although the transition from childhood to adolescence is a difficult period for any pre-teenager, the developing body poses particular challenges for girls. Early adolescence has been found to be a period when girls are at risk for developing disordered eating patterns and body dissatisfaction (Barker \& Galambos, 2003; Graber, Archibald, \& Brooks-Gunn, 1999; Levine \& Piran, 2004; Levine \& Smolak, 2001; Piran, Levine, \& Steiner-Adair, 1999; Smolak, 2004). This is also a time when sexual harassment becomes a widespread problem for girls (AAUW, 1993, AAUW, 2001; Murnen \& Smolak, 2000). Frederickson and Roberts (1997) argue that the experience of sexual harassment can cause heightened body self-consciousness, which can lead to eating problems and other unhealthy behaviour (Barker \& Galambos, 2003; Hofschire \& Greenberg, 2002). In the present study, we investigated this link by interviewing girls about the kinds of harassment directed at their bodies and the impact of this behaviour on their body practices. This paper is a report on our findings taken up in the context of a critique of the health curricula in schools.

Our study combines three phenomena that often have been studied separately: weight- and shape-related teasing, sexual harassment, and racial harassment. We consider how these different forms of negative verbal commentary constitute the bodybased harassment directed at middle-school girls. We use the term "body-based harassment" to encompass all derogatory or objectifying comments directed towards a girl's body. In our research in senior elementary schools, girls have told us this harassment starts from the ages of 8 or 9 and has a direct impact on their body perceptions and practices (Rice \& Larkin, 2001). Many described various food and weight monitoring activities they have adopted to deal with body dissatisfaction and to 
stave off further body-demeaning comments. While a number of studies have found that such weight and body-shape related "teasing" can lead to problem eating in middleschool girls, many fail to label this behaviour as harassment (see Barker \& Galambos, 2003; Shroff \& Thompson, 2004; van den Berg, Wertheim, Thompson, \& Paxton, 2002), a term more capable of taking into account the intersection of the body with inequitable social systems. When negative body comments are described euphemistically as "teasing," the potentially serious effects can be dismissed because the term carries less systemic weight. A few studies have documented the adverse impact of harassment on body esteem and eating patterns (see, for example, Levine, Smolak, Moodey, Schuman, \& Hessen, 1994; Murnen \& Smolak, 2000; Piran, 1999). In naming the taunting as harassment, these researchers were better able to explore the sexism, racism, classism, and other discriminatory factors that influence body-regulating behaviour, something Levine and Piran (2004) advocate in their critical perspectives approach to prevention education.

This paper will focus specifically on body dissatisfaction in girls. While there is increasing concern about negative body esteem in boys, the evidence shows that body regulation practices follow different patterns for males and females (Barker \& Galambos, 2003; Groesz, Levine, \& Murnen, 2002; McCabe \& Ricciardelli, 2001; McCabe, Ricciardelli, \& Finemore, 2002; Polivy, Herman, Mills, \& Wheeler, 2003; Walcott, Pratt, \& Patel, 2003). In their study with students in grades 10 and 11 , Hofschire and Greenberg (2002) found that

... boys who expressed dissatisfaction with their bodies had different concerns and methods for improving themselves. Whereas girls favored thinness and diet 
as a means for achieving improvement, boys idealized larger, more muscular figures and were more likely to exercise. (p. 146)

We know that over $90 \%$ of those diagnosed with eating disorders are women (Walcott et al., 2003). There is a dramatic increase in weight control behaviour as girls go through the pubertal process (Smolak \& Levine, 1996). In a Canadian study of 1739 adolescent girls, $13 \%$ of those aged $12-14$ and $16 \%$ of those aged $15-18$ had scores on the Eating Attitudes Test-26 (EAT-26) above the recommended cut-off for disordered eating. Twenty-three percent of the sample was currently dieting to lose weight, $15 \%$ reported binge eating, $8.2 \%$ reported self-induced vomiting and $2.4 \%$ had used diet pills (Jones, Bennett, Olmsted, Lawson, \& Rodin, 2001). The interplay of gender with class, race, ethnicity, acculturation, and able-bodiedness can create different reasons for weight preoccupation and body dissatisfaction but these are common problems for girls (Larkin, Rice, \& Russell, 1996; Piran, 1999, Rice and Larkin, 2001).

Weight concerns in pre-teens have been found to predict the onset of eating problems in later adolescence, although it is unclear whether or not eating disorders are a common end result (Smolak, 1999). What is evident in our research (Rice \& Larkin, 2001 ) is the extent to which girls begin to engage in extreme body modification practices in response to comments about their weight and physical appearance. Through such harassment, girls get the message that their bodies are potential or actual problems and many begin to experiment with harmful solutions, such as starving, binging, purging, and other attempts at body alteration unrelated to food and eating. $A$ preoccupation with eating behaviour in most research studies has prevented an 
examination of the full range of body modifying practices that girls take on in response to negative comments about their bodies, something we address in this paper.

The field of eating disorders prevention has just started to incorporate components in prevention programs that address the challenges girls face as they move into adolescence (Smolak, 1999). Socio-cultural and feminist models point to the importance of moving prevention programs from a focus on the attitudes and behaviour of individual girls to a consideration of broader socio-cultural factors (Larkin et al., 1996; Nasser \& Katzman, 1999; Nasser, 1997, Piran, 1999, Thompson, 1994). With a fuller integration of culture and gender issues into analyses of eating disorders, body dissatisfaction and weight preoccupation are being considered in the wider context of race, acculturation, identity, and immigration (Nasser \& Katzman, 1999; Thompson, 1994). A global perspective on eating disorders has highlighted the limitations of the dominant "pressure for thinness" model, which fails to capture the range of etiological factors affecting the body regulation practices of diverse girls. Nasser and Katzman (1999) argue that, for many girls, the quest for thinness is not simply a matter of "cosmetic compliance" (p. 37). Issues of transition and identity may play a more prominent role.

The tendency to locate eating disorders in an obsession with slenderness can reinforce demeaning stereotypes of naïve young women controlled by media images of thin femininity, a perspective that fails to capture the range and complexity of young women's embodied experiences (Evans, Rich, \& Holroyd, 2004). We agree with Levine and Piran (2004) about the need for theories of eating disorders 
... [that] go beyond pressures for thinness to examine critically factors such as the objectification of women's bodies or the spectrum of violation of body ownership ... along the dimensions of gender, race, socio-economic status, sexual orientation, and other factors ... (p. 63)

To date, very little prevention work has dealt with this wider spectrum of body image issues (Rice \& Russell, 2002). Before we can address this gap in school curricula, however, we need a better understanding of the factors that influence the body perceptions of girls:

... [d]eveloping programs without empirical information about risk and protective factors raises the possibility that the wrong topics will be emphasized in the curricula. This risk is particularly high in multicultural student groups, because research suggests that the symptoms and etiological factors associated with anorexia nervosa and bulimia show cultural differences ... Selection of the wrong topics might lead to undesirable outcomes and to reduced effectiveness. (Smolak, 1999, p. 92)

The research reported on here is a response to these concerns. In this paper we read the empirical data we collected in a study with grades 7 and 8 girls against content of body image components of health curricula in schools. We determine the extent to which curricula reflect body image concerns identified by girls and use the data to make some recommendations for curricula modifications.

\section{Methodology}


This study is a combination of two methods: (1) a discourse analysis of sections of middle-school health curricula that deal with harassment, body image, and eating behaviour and (2) research with middle-school girls on the experience and impact of harassing comments about their bodies.

\section{Curricula analysis}

Discourse analysis is described by Gavey (1997) as a method for critical study of language use in spoken and written communication. Discourse analysis involves a careful reading of texts, including research interviews and school curricula, to uncover underlying patterns of meaning. Starting with the close study of a specific communication, discourse analysis moves outward toward the broad social picture to examine how language use reproduces or challenges power relations among social groups.

We used discourse analysis to identify the ways body image issues are taken up in health curricula in schools. We selected the Ontario, Canada public school health curriculum as our text for this analysis because our research was conducted with female students in Ontario schools. Since the health curriculum is mandatory for all students from grades 1 to 8 , we assumed all female students had been exposed to similar information. We acknowledge, however, that the presentation of this information may have varied from teacher to teacher.

\section{Research in schools}

Our research was conducted with grades 7 and 8 girls in four Ontario schools. Two schools were located in a small Ontario city, one school was in a town, and the other was in a rural area. The research in schools was conducted in two stages: 
educational workshops and individual interviews. Both the workshops and interviews were conducted by a research team that included academic researchers (Larkin and Rice), a graduate student (Cheddie), community health nurses (Vandepol and Kelterborn), and a school guidance counsellor (Bennett). All members of the universitycommunity team were involved in facilitating the workshops, developing the interview schedule, conducting individual interviews, and transcribing and analyzing the data.

\section{Stage one: workshops}

The workshops were designed as educational sessions to introduce the students to the concepts of body image and harassment and to provide opportunities to explore ways these phenomena might be linked. Information from the workshop discussions was used by the team to develop a list of questions for the individual interviews we conducted with girls in stage two of the research (see the Appendix). Female students who attended the workshops as part of an extra-curricular school activity were invited to participate in an individual interview to discuss the messages they receive about their bodies as well as their diverse body practices.

\section{Stage two: interviews}

Forty-five students who had attended the educational workshops agreed to be interviewed. Based on an analysis of the demographic information provided by each interviewee, the girls we interviewed were primarily from working class backgrounds, a significant number (about 20\%) were of Eastern European origin and about 15\% identified as girls of colour. The remaining sample self-identified as Canadian born and Caucasian. The one-on-one interviews were conducted by members of the research 
team. Each interview was approximately $60 \mathrm{~min}$. Interviews were tape-recorded and transcribed.

\section{Data analysis}

A modified grounded theory approach guided analysis of the interview data. Based on emerging themes, commonalities, and major differences, a coding framework was developed. Each transcript was coded separately by the two authors who then met to discuss similarities and differences in their coding. Samples of coded data were returned to the larger team for their feedback and verification. The coding scheme was revised based on their input.

We begin the discussion of our analysis by identifying the dominant discourses in the body image components of the health curriculum in Ontario schools. We then go on to consider these discourses in the context of the body image issues identified by girls.

\section{Healthy eating, healthy weights: dominant discourses in the Ontario health curriculum}

The general health curriculum guidelines for grades $1-8$ are divided into four categories: (1) healthy eating; (2) growth and development; (3) personal safety and injury prevention; and (4) substance use and abuse. Body image and eating disorders are covered under the section on "Healthy Eating" (Ministry of Education and Training, 1998). In grades 7 and 8 , the grades of the girls we interviewed, the focus for teachers is on helping students to make good food choices and to develop strategies for maintaining a healthy body weight. The specific learning tasks are to:

Grade 7 
- examine the effects of healthy eating and regular physical activity on body size and shape, and on self-esteem;

- describe how our body image influences our food choices;

- identify factors affecting healthy body weight (e.g., food intake, growth spurts, physical activity/inactivity).

Grade 8

- analyse the effects of undereating (e.g., as a result of bulimia or sports dieting) and overeating (e.g., obesity) on health and well-being;

- identify ways to maintain a healthy body weight (e.g., physical activity). 1

The discourse on healthy eating, healthy weights that informs the Ontario health curriculum is consistent with the focus of many prevention programs (for reviews see Heinze, Wertheim, \& Kashima, 2000; Levine \& Smolak, 2001; Nichter, Vuckovic, \& Parker, 1999; O’Dea \& Abraham, 2000; Piran, 1999, Rosenvinge and Gresko, 1997), including those designed for young people:

... the most common prevention strategy used for body dissatisfaction and disordered eating among children and adolescents has been a psychoeducational one. Prevention efforts have sought to improve children and adolescents' knowledge of nutrition, health eating, and exercise. (Littleton \& Ollendick, 2003, p. 58)

\footnotetext{
${ }^{1}$ Health curriculum guidelines and specific learning tasks are excerpted from The Ontario Curriculum, Grades 1-8, Health and Physical Education, pp. 18, 19. Published by the Ministry of Education and Training, 1998.
} 
In critiquing these programs, Littleton and Ollendick (2003) argue that the focus on nutritional knowledge is misguided:

... The primary shortcoming of the current approaches to prevention appears to be the assumption that it is a lack of knowledge regarding healthy eating that lead to these problems and therefore, provision of this knowledge will be sufficient to improve healthy eating and decrease disordered eating .... Results of these prevention programs clearly demonstrate that changes in knowledge are not sufficient to alter disordered eating behavior ... several of these programs have produced substantial improvements in knowledge with little or no effect on body image dissatisfaction or disordered behavior. (p. 61)

In proposing alternative approaches, Littleton and Ollendick argue for more emphasis on "enacting changes in the school environment" (2003, p. 63), something missing from a body image curriculum that situates the problem in the discourses of food choices, eating behaviour, and weight management. Within these discourses, health becomes an individual responsibility independent of the structural constraints that impact on health practices (Evans et al., 2004).

In the curriculum, harassment and other environmental factors are not acknowledged as reasons girls (or boys) may develop body image problems. Instead, an ethic of individual responsibility for causes and cures of body image and eating problems prevails. While body image and eating disorders are covered under "Healthy Eating," harassment is included under the "Personal Safety and Injury Prevention" component of the curriculum (Ministry of Education and Training, 1998). The link between body dissatisfaction, eating problems, and harassment (Larkin et al., 1996) is 
lost in this division. In our study, body-based harassment was a major cause of the body dissatisfaction that led many girls to adopt body modification strategies that had serious consequences for their physical and emotional health.

I know a couple [girls] who got really bad eating disorders because people were calling them fat ... it really gets to them.

If the comment is ... that you are a pig, then the girl will stop eating literally until she starves herself so much that she just has to eat ... some girls take pills to make them throw up.

Interwoven throughout discourses of health eating, healthy weights in the curriculum is the imperative of bodily self-control. The grade 8 program guidelines specify "the effects of undereating (e.g., as a result of bulimia or sports dieting) and overeating (e.g., obesity) on health and well-being" but the causes of problem eating or other body regulation practices are not adequately explored (Ministry of Education and Training, 1998, p. 19). Pressure to eat the "right" foods, the "right" way, to obtain the "right" shape can operate as a form of moral regulation which reduces health to "a personal attribute, an achievement, or ... an individual problem to be addressed" (Evans et al., 2004, p. 135).

In general, our research suggests that the healthy eating, healthy weights discourse may actually increase the anxiety for girls who are struggling with body issues and eating problems by encouraging further self-monitoring. Through an analysis of the data collected in our interviews we have identified five more specific limitations of the healthy eating, healthy weights approach used in the school curriculum: (1) it sends contradictory messages; (2) it increases anxieties about body weight; (3) it ignores the 
multiple causes of eating problems; (4) it marginalizes issues most relevant to racialized girls; and (5) it ignores dilemmas associated with physical development. These limitations are described in the following sections.

\section{Sending contradictory messages}

In many prevention programs, improving nutritional knowledge is proposed as the primary prevention strategy for food and weight problems. This is the most common primary prevention strategy, despite the lack of evidence supporting its continued use. For more than a decade, researchers have been reporting the lack of clear connection between increasing nutritional knowledge and decreasing problem eating (Graber \& Brooks-Gunn, 1996; Searles, Terry, \& Amos, 1986). The lack of clear connection between teaching nutrition and preventing eating problems alone raises questions about the efficacy of promoting healthy eating as a weight and shape preoccupation strategy. In addition, Piran (1999) argues that:

[a]lthough I support the importance of healthy lifestyle training that includes principles of healthy eating and healthy exercise, I tend to separate such training from prevention programs for BWSP [body-weight and shape preoccupation]. In my view, one of the significant goals of a prevention program for BWSP is to dispel cultural myths that maintain that a woman's body is inherently deficient and in need of external management and control (Bordo, 1993). The inclusion of a weight management program may contradict this goal. (p. 156).

We agree with Piran's argument that conflating healthy eating and lifestyle education with lessons on body image and eating problems sends contradictory 
messages to girls. On the one hand, girls learn the importance of managing their eating and weight, and on the other, they learn the conflicting value of body acceptance.

Some health educators have expressed concern that girls might read healthy eating messages as an injunction to lose weight "adding to the pressures to be thinner which they face already" (Dixey, 1998, p. 31). This was the situation for one of the girls in a study conducted by Evans et al. (2004):

Carrie commented that she "honestly thought" that she "was just being healthy by cutting out fats entirely" and noted that this was how her eating disorder started (p. 135).

In our study, girls had clearly learned to "watch what they eat" as a primary strategy for weight reduction:

I think it's ok to diet as long as you don't overdo it. You don't need to completely make sure you eat this much on this amount of days. Just watch what you eat, like not so much junk food, more of the health stuff ... I think that who you are is who you are, except I can't really get that through my head to think of it for me.

Within the healthy eating discourse, young women learn about the importance of food and weight monitoring. This may lead to a lifelong preoccupation with eating and body size, an outcome that can work against the adoption of healthy lifestyle practices (Chapman, 1999).

\section{Increasing anxieties about body weight}

For girls, negative body image has been found to be tied to perceptions of body size, and this subjective view is more predictive of dieting behaviours than actual weight 
(Phelps, Dempsey, Sapia, \& Nelson, 1999, p. 164). In studies on body image, it is not uncommon for girls within the normal weight range to express dissatisfaction with their bodies and a desire to be thinner (Engström \& Norring, 2001; Lovejoy, 2001, Polivy et al., 2003; Young-Hyman, Schlundt, Herman-Wenderoth, \& Bozylinski, 2003). Bodybased harassment appears to play a role in such distorted body perception. In a sample of 470 grade 10 girls, van den Berg et al., 2002, van den Berg et al., 2002 found that "body dissatisfaction was predicted more strongly by teasing than actual body size" ( $p$. 49). This was evident in the accounts of the girls we interviewed. For example, girls who were called fat, even when they were underweight by medical standards engaged in extreme body regulation practices such as starving, binging, and purging:

... [girls] feel they're fat when they're little ... the guys call them fat because they think it's funny ... so [the girls] will stop eating.

The popular medical consensus that girls with eating disorders experience greater body image disturbance and distortion than girls without eating disorders (American Psychiatric Association, Diagnostic and Statistical Manual of Mental Disorders, 1994) is questionable if we consider that most of the girls we interviewed were dissatisfied with their bodies. Many distorted their body size, calling themselves fat when they were well within a normal weight range:
A friend of mine ... She started to starve herself because somebody said [she] was fat but she's really not, she's perfect ...

This finding is consistent with studies investigating body dissatisfaction in women with and without eating disorders; interviews with both groups have shown that they 
share a sense of body dissatisfaction and distorted body perception (HaworthHoeppner, 1999).

Although comments about being fat were more common, girls were also hassled for being overly slim. The pressure for thinness model of problem eating, cannot account for the growing stigma attached to bodies perceived as being too thin. Labels such as "Queen Anorexia" were used to hassle girls considered to be underweight. As evident in the following accounts, thinness is not always a desired bodily state:

I'm not really underweight, but I don't weigh a lot, but they always say, "You're anorexic and everything."

Last year [this girl] was in my class and she was really thin and people called her anorexic ... I think she cried but she hid it because she didn't want the boys to know they upset her.

... and if you're really thin they go, "what are you going to throw up now?"

Our research shows that girls get negative comments about their weight regardless of their body size or eating patterns. These external messages appear to carry more currency than standard measures of actual weight. As one girl explained, "If someone keeps telling you you're too fat or too skinny ... you're going to believe it after awhile." When girls have a distorted view of their physical size, pressure to maintain a healthy body weight is unlikely to correct problem eating:

My friend thinks she's got a big butt but she doesn't really. She calls herself fat and she's way skinnier than I am ... A lot of people believe what other people say 
In the context of harassing comments about body size, the curriculum focus on healthy body weight may actually exacerbate girls' anxieties as they struggle to attain an illusive body norm:

l'd say almost every single girl gets comments that they're either too fat or too skinny. I don't think people understand what the normal weight is supposed to be.

Amplified by body-based harassment, healthy weights messages may shape girls' unhealthy body perceptions and practices by teaching them the negative cultural meanings given to differences in body sizes.

\section{Ignoring the multiple causes of eating problems}

Global forces such as immigration, acculturation, and modernization are believed to be creating societal pressures that contribute to the eating pathology and body dissatisfaction of diverse groups of women (Perez, Voelz, Pettit, \& Joiner, 2002; Walcott et al., 2003). According to Nasser and Katzman (1999):

The experience of women from other ethnicities and cultures has accumulated after the publication of several case reports of anorexia nervosa in the black communities in both the United States and the United Kingdom ... These authors observed the psychological problems of girls who struggled with their "racial identity" and the powerful need to fit into a new society, hoping to become "integrated" through rigid dieting and adoption of prevailing social standards of thinness ... Immigration and acculturation were regarded in a great number of these studies to be behind the immigrant's susceptibility to developing weight concerns. (p. 30) 
When some of the girls we interviewed came to Canada, they were socialized into accepting North American weight standards and eating patterns, norms they described as different from those of their culture of origin. Their attempt to develop these standards was more about "fitting in" than being thin and beautiful. A young woman from Romania explained it this way:

I'm sitting at the store and I'm thinking of a bag or an orange juice and I think, "Do I need this bag of chips, is it good for me?" Usually the answer is always "no." I hate that ... I always look at the back to see what is in things, the grams of fat. Grams of fat add up to a pound and that's what I hate. In the country that I come from, fat is what guys want 'cause if you're fat you're rich. You can buy all the good food and good meat. And if you're a skinny little girl you're considered not good enough. That's one of the good things about my country Romania.

For some immigrant girls, weight preoccupation is said to be part of the social process of acculturation. Wildes and Emery (2001) define acculturation as "the process of psychosocial change that occurs when a group or individual acquires the cultural values, language, norms, and behaviour of a dominant society" (p. 524). The strain of this adaptation is believed to create a kind of "acculturative stress" (Perez et al., 2002, p. 442) that may get played out in eating behaviour (Walcott et al., 2003).

Thompson (1992) proposes that, for many women, eating problems may begin as ways of coping with "various traumas including sexual abuse, racism, classism, heterosexism, and poverty" (p. 547). There is an extensive body of literature on the connection between women's troubled relationship with food and a past history of sexual trauma and physical abuse (Larkin et al., 1996, Rice, 1996, Thompson, 1994; 
Vanderlinden, Vandereychen, van Dyck, \& Vertommen, 1993; Waller, Hamilton, Rose, Sumra, \& Baldwin, 1993; Wooley, 1994). The origins of eating problems in Black women have been linked to a variety of oppressive factors, such as racial isolation, harassment, and stigmatization during childhood (Rice, 2002; Rice \& Russell, 1995; Thompson, 1992), and the everyday stress of being overworked and undervalued at home and on the job (Avery, 1990).

There is evidence that women of colour women who internalize dominant white beauty norms are more likely to develop eating disorders than those who have a strong identification with their minority culture (lyer \& Haslam, 2003). Black women, for example, have been found to have fewer eating pathologies than white women (Croll, Neumark-Sztainer, Story \& Ireland, 2002; Polivy et al., 2003; Wildes \& Emery, 2001), although this finding has also been disputed (Rubin, Fitts, \& Becker, 2003; Shaw, Ramirez, Trost, Randall, \& Stice, 2004). Of relevance to our discussion is the perception that "culture" can operate as a protective shield from pressure to achieve an unattainable beauty ideal. For Poran (2002) the idea of a Black culture is an essentialist one. In her study, Black women who had positive body esteem were highly articulate about racist notions of beauty. In their case, the buffer appeared to be a critical race consciousness, not culture.

If we consider racism as a contributing factor to body image disturbance, we shift the focus from the processes of acculturation and ethnic identification to more systemic forms of discrimination such as 'racial teasing':

... racial teasing may be an important but neglected factor in the eating and body image disturbance among minority women ... researchers and theorists may 
need to look beyond women's relations to the dominant and origin cultures. If a history of being hurtfully taunted about one's ethnic appearance is associated with eating and body image disturbance, then it may be the majority culture's response to the minority individual, not just her psychological accommodation to it or estrangement from her ethnic origins that plays a role in these disturbances. (lyer \& Haslam, 2003, p.146)

In our research, girls' anxieties about body weight were heightened by 'teasing' (read: harassment), which drew on racist stereotypes about their bodies and applied pressure to conform to white, anglo-saxon norms:

And sometimes, if they're skinnier than most ... 'cause they feel that if they eat they'll get teased more because they have a different background than everyone else. [So if] they're really skinny [people say], "Oh my gosh, all Oriental people are anorexic." So you'll get teased about being anorexic because you tried to stay skinny.

By taking gender as the primary unit of analysis, research in the area of eating disorders may be reinforcing the notion that eating problems are the province of white, middle-class females. But, as Bordo (1999b) points out, this view sees racialized women "as outside the loop of dominant culture ... a mistake that has left many women feeling stranded alone with a disorder that they weren't ... supposed' to have and that clinicians dismissed" (p. 134). The health eating, healthy weights discourse reinforces individual responsibility for eating problems with no recognition of the external machinery of racism and other discriminatory practices that have an impact on the eating patterns of girls. 


\section{Marginalizing issues most relevant to racialized girls}

Clichés about various ethnic traditions offering alternative standards of beauty have contributed to the perception that girls of colour are protected from pressures to achieve the dominant version of white, heterosexual feminine beauty. Recognition that the incidence of body image problems among women of colour has been seriously underestimated (Badwell, 1997, Bordo, 1999b, Thompson, 1994) was supported in our research through the numerous accounts of racist comments that influenced the body modification practices of minority girls. For some students, attempts at physical alterations were a response to comments about skin colour, hair texture, cultural dress, and other stereotypical notions of racialized bodies:

My friend heard racist comments so she would wear a lot of powder on her face to make her lighter.

... sometimes, l've heard ... really rude comments ... like racist ... They call you the "n" word. They make fun of you ... You] try to wear long stuff so your skin doesn't show ... some bleach their skin.

In current body prevention work, the obsession with comparing rates of eating disorders between white women and women of colour (Croll et al., 2002; Levine \& Smolak, 2001; Perez et al., 2002, Walcott et al., 2003) may be off the mark in getting at the body image issues of greatest concern for racialized girls. In their research with African American and Latino women, Rubin, Fitts, and Becker (2003) found that "the perceived devaluation of 'ethnic' looks by the dominant culture" (p. 63) was a central theme in every focus group. Negative messages about skin colour and hair created 
pressure to conform to white beauty ideals. Body-based harassment, in the form of "racist teasing" is implicated in this process:

By drawing hurtful attention to their ethnically distinctive features, racial teasing might lead minority women to adopt the beauty norms of the dominant culture, disidentify with their host culture, and experience identity problems, distress, and self-denigration, thereby promoting eating and body image disturbance. (lyer \& Haslam, 2003, p. 143)

The healthy eating, healthy weights approach does not address the body image concerns of racialized girls and how these concerns might be related to ideals of beauty in our society. As a result, the curriculum fails to incorporate the range of factors that influence the body regulation practices of diverse girls. Addressing forms of racist bodybased harassment in prevention programs will provide students with opportunities to discuss skin bleaching and other body regulation practices that may have serious health consequences for girls of colour.

\section{Ignoring dilemmas associated with physical development}

Many girls we interviewed had attempted to modify their bodies for reasons that were related to body development rather than body size. Comments related to girls "early" or "late" breast development may contribute to the rise in girls' eating problems around puberty (Graber et al., 1999). There is evidence, for example, that early maturers start dieting sooner (Littleton \& Ollendick, 2003; Smolak, 1999) and that late maturers develop body dissatisfaction for having a body that fails to "qualify as womanly" (Rice, 2003, p. 276). A focus on weight management in the school curriculum 
ignores the messages girls get about various body parts and the extreme forms of body modification they begin to consider.

[Girls who develop late], they get called a carpenter's dream or flat as a board and stuff like that.

My friend [Rebecca] she's like, "I'm going to get implants" ... cause she got teased for being flat ... my friend sounded very serious.

One estimate put the number of cosmetic operations on under 18-year olds in Canada to be about 2000 per year and rising (Rumak, 2001). An article in the Globe \& Mail, a national newspaper (MacDonald, 2001), provides evidence that cosmetic surgery is being promoted as a reasonable solution to the body-based harassment experienced by girls. In the following cases, racist and sexist body-related comments are euphemistically labelled as teasing with cosmetic surgery promoted as a reasonable solution to the emotional effects:

A few years ago [Dr. Claudio De Lorenzi] operated on a 15-year-old girl to give her a B cup ... her doctor wrote me a letter saying this girl's emotional problems stem mainly from her appearance. She doesn't have the ability to withstand the teasing. She came into my office with her head bowed, her bangs covering her whole face ... I remember when she came back, she had her hair up, she was a totally different person ... the amazing difference was in her self-confidence. It made me think sometimes it is justifiable. (MacDonald, 2001, p. R25)

Despite the fact that shoddy surgery can leave patients with eyes that can't close at all or freakishly high folds, the procedure is commonly condoned, even 
encouraged by many parents ... in 1978, Dr. Son-Hing did maybe one a month. He now does two or three a day, on patients whose average age is $18 \ldots$ But he does believe there is an argument to be made for younger patients, especially those being teased or bullied mercilessly ... Some kids get teased. In the Asian population, they're referred to as "pig eyes." The Caucasians call them "slit eyes." (MacDonald, 2001, p. R25)

What's insinuated in these accounts is the rhetoric of empowerment through cosmetic surgery (Bordo, 1999a). In the new discourse of girl power, young women are pressured to resist the alleged victimization message of feminism by taking charge of their lives. There is strong evidence that they do. The girls we interviewed were not passive recipients of physically demeaning comments; most were actively engaged in practices designed to reshape and modify their bodies. Along with Bordo (1999a) we are concerned about the co-opting of female agency under the guise of "power feminism":

What is masked by the rhetoric ("taking control of one's life" through cosmetic surgery), I argue, is a consumer culture that depends on the continual creation and proliferation of [female] "defect"; that is always making us feel bad about ourselves about the same time as it pumps us with our own "agency": take charge, "Just do It!" (p. 21)

In general, body-based harassment played a major role in relaying messages that constructed girls' bodies as problem sites that needed to be corrected. Our recommendations for improving the curriculum have to do with expanding the focus beyond weight to include the various socio-cultural factors that influence the range of 
body monitoring practices taken up by diverse girls. We provide a few examples in the context of our concluding comments.

\section{Conclusion: mainstreaming body equity}

In this paper we used data collected from grades 7 and 8 girls to demonstrate how the healthy eating, healthy weights focus of the current elementary health curriculum is a problematic approach to preventing body dissatisfaction and problems with eating. In general, a focus on weight management ignores the cultural factors that influence girls' body practices. In our research, body-based comments played a significant role in girls' attitudes about their body and the eating patterns and regulation practices they undertook.

Increasingly, body image researchers recognize the need to transcend the field's narrow focus on problems with weight and shape, yet few have addressed girls' diverse body image concerns (Cash, 2004, Levine and Piran, 2004). Integrating harassment into body image discussions will help to ensure that schools address systemic factors such as racism, sexism and other discriminatory practices that can create body dissatisfaction in girls. To take this a step further, we propose mainstreaming body equity through the elementary school curriculum. By "body equity" we mean an approach that promotes the acceptance of diverse bodies within the school population (Rice \& Russell, 2002, p. 15). Mainstreaming body equity in schools implies that issues related to the body should be regarded as cross cutting in all school subjects (Sibiya, 2000). For example, in mathematics, teachers could introduce the concept of the "norm" by teaching students how norms have been determined mathematically. This might 
include an exploration of how 19th century statisticians introduced the notion of a normal body (Davis, 1995).

Finally, to be truly effective, prevention programs must extend beyond the classroom to include changes in the social environment. Raising awareness about the socio-cultural factors of body-based harassment can increase girls' anxieties if there is no parallel effort to address these larger concerns (Piran, 1999). While many school boards have sexual, racial, and homophobic harassment policies, body-based harassment can often slip though the cracks (AAUW, 2001; Rice \& Russell, 2002; Larkin et al., 1996). For this reason, we believe it makes sense to advocate for inclusion of the language of body-based or appearance related harassment into pre-existing policies.

There is strong evidence that changing existing behaviour through a school curriculum is extremely difficult (Smolak, 1999). This means that interventions on body image and weight preoccupation are most effective at the elementary school level before problem eating patterns and negative body image are firmly entrenched. Given this huge responsibility, it is important that we expand our thinking to consider a wider range of body modification practices and the systemic factors that impact on girls' body esteem.

\section{Acknowledgements}

The authors acknowledge the contributions of Marlene Bennett, Stephanie Cheddie, Marion Kelterborn, and Muriel Vandepol, and the support of the Waterloo Region District School Board and the Waterloo Community Health Department. 


\section{Appendix: Interview questions}

1. Do girls hear comments about their bodies? If so, can you give some specific examples?

2. What kinds of comments do girls hear from guys? Other girls? Adults? Pop culture? Friends? Families? Strangers? Teachers? Coaches? Doctors and nurses?

3. What comments do girls hear about their weight? Height? Breasts? Facial features like eyes or noses? Skin problems? Body size and shape? Hair styles and colour? Skin tone and colour? Their periods? Any other body parts? Sexual practices? Dress? Athletic ability? Disabilities?

4. At what age do you think these messages/comments start?

5. Where are these comments made and who makes them?

6. What about girls from different cultural groups? Do Portuguese girls get comments that are different from girls from other cultural groups? If so, what have you heard?

7. Do Black girls get comments that are different from girls from other groups? If so, what have you heard?

8. Do White girls get comments that are different from girls from other groups? If so, what have you heard?

9. Do Asian girls get comments that are different from girls from other groups? If so, what have you heard?

10. Do Mennonite girls get comments that are different from girls from other groups? If so, what have you heard? 
11. Do girls who do not have a lot of money get comments that are different from girls from other groups? If so, what have you heard?

12. Do girls who develop early get comments about their bodies? If so, what have you heard?

13. Do girls who develop late get comments about their bodies? If so, what have you heard?

14. Do girls get comments about being tomboys?

15. How do these comments/messages make girls feel about their bodies? About themselves?

16. Do you think these comments cause girls to change the way they behave? Dress? Eat? Feel about their bodies?

17. (Review the term "body image" as discussed in the focus groups.) Do you think any girls your age have body image problems? Why? Why not? What kind of body image problems do you see?

18. What is your idea of an ideal body for girls?

19. What do girls do to achieve their ideal body?

20. What are your attitudes/feelings about your body?

21. What do you think about what girls do to change their looks?

22. What clothing styles do you like to wear? What styles are popular at your school?

23. Do you wear make-up? Why or why not?

24. What types of activities are you involved in? Do you participate in physical activity? Why or why not?

25. Do you think some girls your age have eating problems? 
26. Do you think comments about girls' bodies could lead girls to develop body image problems? Eating problems? If so, how?

27. If you had a friend who had an eating problem, what would you do? What would you say to her? What kind of advice would you give her?

28. What are your eating habits? Have you ever dieted?

29. Has your body changed in the last few years? If so, how has it changed? How do you feel about these changes?

30. What messages/comments do you get about your body? What comments/messages have you heard in the past?

31. What is one thing girls don't need to hear about their bodies? Their eating? What is one thing girls need to hear about their bodies? Their eating?

32. What can schools/parents/friends/guys do to help girls feel good about their bodies?

\section{References}

American Association of University Women. (1993). Hostile hallways: The AAUW survey on sexual harassment in America's schools. Washington, DC: Author. American Association of University Women. (2001, May). Hostile hallways: Bullying, teasing, and sexual harassment in school. Washington, DC: Author.

American Psychiatric Association. (1994). Diagnostic and statistical manual of eating disorders (4th ed.). Washington, D.C: Author.

Avery, B. (1990). Breathing life into ourselves. The evolution of the National Black Women's Health Project. In E. White (Ed.), The Black women's health book: Speaking for ourselves (pp. 4-10). Seattle, WA: Seal Press. 
Badwell, H. (1997). Moving through my body. In S. K. Chatree (Ed.), Voices of strength: An anthology by emerging young South Asian and Indo-Caribbean women and artists (pp. 16-18). Toronto, Ont., Canada Shatki Kee Chatree.

Barker, E. T., \& Galambos, N. L. (2003). Body dissatisfaction of adolescent girls and boys: Risk and resources factors. Journal of Early Adolescence, 23, 141-165.

Barker, E. T., \& Galambos, N. L. (2003). Body dissatisfaction of adolescent girls and boys: Risk and resources factors. Journal of Early Adolescence, 23, 141-165.

Bordo, S. (1999a). Introduction. Twilight zones: The hidden life of cultural images from Plato to O.J. (pp. 1-25). Berkeley, CA: University of California Press.

Bordo, S. (1999b). Never just pictures. Twilight zones: The hidden life of cultural images from Plato to O.J. (pp. 107-138). Berke- ley, CA: University of California Press.

Cash, T. (2004). Body image: Past, present, and future [Electronic version]. Body Image, 1, 1-5.

Chapman, G. (1999). From "dieting" to "healthy eating:" An exploration of shifting constructions of eating for weight control. In J. Sobal, \& D. Maurer (Eds.), Interpreting weight: The social management of fatness and thinness (pp. 73-87). New York: Aldine De Gruyter.

Croll, J., Neumark-Sztainer, D., Story, M., \& Ireland, M. (2002). Prevalence and risk and protective factors related to disordered eating behaviors among adolescents: Relationship to gender and ethnicity. Journal of Adolescent Health, 31, 166-175. Davis, L. (1995). Enforcing normalcy: Disability, deafness and the body. New York: Verso Press. 
Dixey, R. (1998). Healthy eating in schools, overweight and "eating disorders": Are they connected? Educational Review, 50, 29-35.

Engström, I., \& Norring, C. (2001). Risk for binge eating in a non-clinical Swedish adolescent sample: A repeated measure study. European Eating Disorders Review, 9, 427-441.

Evans, J., Rich, E., \& Holroyd, R. (2004). Disordered eating and disordered schooling: What schools do to middle class girls. British Journal of Sociology of Education, 25, 123-142.

Frederickson, B., \& Roberts, T. (1997). Objectification theory: Toward understanding women's lived experiences and mental health risks. Psychology of Women Quarterly, 21, 173-206.

Gavey, N. (1997). Feminist poststructuralism and discourse analysis. In M. Gergen, \& S. Davis (Eds.), Toward a new psychology of gender (pp. 49-64). New York: Routledge.

Graber, J., Archibald, A. B., \& Brooks-Gunn, J. (1999). The role of parents in the emergences, maintenance, and prevention of eating problems and disorders. In $\mathrm{N}$.

Piran, M. P. Levine, \& C. Steiner-Adair (Eds.), Preventing eating disorders: A handbook of interventions and special challenges (pp. 44-62). Philadelphia: Brunner/Mazel.

Graber, J., \& Brooks-Gunn, J. (1996). Prevention of eating problems and disorders: Including parents. Eating Disorders, 4, 348-363. 
Groesz, L., Levine, M., \& Murnen, S. (2002). The effect of experimental presentation of thin media images on body satisfaction: A meta analytic review. International Journal of Eating Disorders, 31(1), 1-16.

Haworth-Hoeppner, S. (1999). Medical discourse on body image: Reconceputalising the differences between women with and without eating disorders. In J. Sobal \& D. Maurer (Eds.), Interpreting weight: The social management of fatness and thinness (pp. 73-87, 89-111). New York: Aldine De Gruyter.

Heinze, V., Wertheim, E., \& Kashima, Y. (2000). An evaluation of the importance of message source and age of recipient in a primary prevention program for eating disorders. Eating Disorders, 8, 131-145.

Hofschire, L. J., \& Greenberg, B. S. (2002). Media's impact on adolescents' body dissatisfaction. In J. D. Brown, J. R. Steele, \& K. Walsh-Childers (Eds.), Sexual teens, sexual media: Investigating media's influence on adolescent sexuality (pp. 125-149). Mahwah, NJ: Lawrence Erlbaum Associates.

lyer, D. S., \& Haslam, N. (2003). Body image and eating disturbance among South Asian-American women: The role of racial teasing. International Journal of Eating Disorders, 34, 142-147.

Jones, J., Bennett, S., Olmsted, M., Lawson, M., \& Rodin, G. (2001). Disordered eating attitudes and behaviours in teenaged girls: A school-based study. Canadian Medical Association Journal, 165, 547-552.

Larkin, J., Rice, C., \& Russell, V. (1996). Slipping through the cracks: Sexual harassment, eating problems, and the problem of embodiment. Eating Disorders, 4, 5-26. 
Levine, M. P., \& Piran, N. (2004). The role of body image in the prevention of eating disorders. Body Image [Electronic version], 1, 57-70.

Levine, M. P., Smolak, L., Moodey, A. F., Schuman, M. D., \& Hessen, L. D. (1994). Normative developmental challenges and dieting and eating disturbances in middle school girls. International Journal of Eating Disorders, 15, 11-20.

Levine, M. P., \& Smolak, L. (2001). Primary prevention of body image disturbances and disordered eating in childhood and early adolescence. In J. K. Thompson, \& L. Smolak (Eds.), Body image, eating disorders, and obesity in youth (pp. 237-260). Baltimore: United Book Press.

Littleton, H. L., \& Ollendick, T. (2003). Negative body image and disordered eating behavior in children and adolescents: What places youth at risk and how can these problems be prevented? Clinical Child and Family Psychology Review, 6, 51-66.

Lovejoy, M. (2001). Disturbances in the social body: Differences in body image and eating problems among African American and White women. Gender and Society, 15, 239-261.

MacDonald, G. (2001, January 15). Girls under the knife. The Globe and Mail, R1-R25. McCabe, M., \& Ricciardelli, L. (2001). Parent, peer, and media influences on body image and strategies to both increase and decrease body size among adolescent boys and girls. Adolescence, 36, 225-240.

McCabe, M. P., Ricciardelli, L. A., \& Finemore, J. (2002). The role of puberty, media and popularity with peers on strategies to increase weight, decrease weight and increase muscle tone among adolescent boys and girls. Journal of Psychosomatic Research, 52, 145-154. 
Ministry of Education and Training. (1998). The Ontario curriculum grades 1-8: Health and physical education. Toronto, Ont., Canada: Author.

Murnen, S., \& Smolak, L. (2000). The experience of sexual harassment among gradeschool students: Early socialization of female subordination? Sex Roles, 43, 1-17. Nasser, M. (1997). Culture and weight consciousness. London: Routledge.

Nasser, M., \& Katzman, M. (1999). Eating disorders: Transcultural perspectives inform prevention. In N. Piran, M. P. Levine, \& C. Steiner-Adair (Eds.), Preventing eating disorders: A handbook of interventions and special challenges (pp. 26-43). Philadelphia: Brunner/Mazel.

Nichter, M., Vuckovic, N., \& Parker, S. (1999). The looking good, feeling good program: A Multi-ethnic intervention for healthy body image, nutrition, and physical activity. In N. Piran, M. P. Levine, \& C. Steiner-Adair (Eds.), Preventing eating disorders: A handbook of interventions and special challenges (pp. 175-193). Philadelphia: Brunner/Mazel.

O'Dea, J., \& Abraham, S. (2000). Improving the body image, eating attitudes, and behaviours of young male and female adolescents: A new educational approach that focuses on self-esteem. International Journal of Eating Disorders, 28, 43-57.

Perez, M., Voelz, Z. R., Pettit, J. W., \& Joiner, T. E. J. (2002). The role of acculturative stress and body dissatisfaction in predicting bulimic symptomatology across ethnic groups. International Journal of Eating Disorders, 31, 442-454.

Phelps, L., Dempsey, M., Sapia, J., \& Nelson, L. (1999). The efficacy of a school-based eating disorder prevention program: Building physical self-esteem and personal competencies. In N. Piran, M. P. Levine, \& C. Steiner-Adair (Eds.), Preventing 
eating disorders: A handbook of interventions and special challenges (pp. 163174). Philadelphia: Brunner/Mazel.

Piran, N. (1999). The reduction of preoccupation with body weight and shape in schools: A feminist approach. In N. Piran, M. P. Levine, \& C. Steiner-Adair (Eds.), Preventing eating disorders: $A$ handbook of interventions and special challenges (pp. 148-159). Philadelphia: Brunner/Mazel.

Piran, N., Levine, M. P., \& Steiner-Adair, C. (1999). Prevention programs for elementary and middle schools. Preventing eating disorders: A handbook of interventions and special challenges (pp. 85-86). Philadelphia: Brunner/Mazel.

Polivy, J., Herman, C. P., Mills, J. S., \& Wheeler, H. B. (2003). Eating disorders in adolescence. In G. R. Adams, \& M. D. Berzonsky (Eds.), Blackwell handbook of adolescence. Black- well handbooks of developmental psychology (pp. 523-549). Malden, MA: Blackwell.

Poran, M. A. (2002). Denying diversity: Perceptions of beauty and social comparison processes among Latino, Black and White women. Sex Roles, 47, 65-82.

Rice, C. (1996). Trauma and eating problems: Expanding the debate. Eating Disorders, 4, 197-237.

Rice, C. (2002). Between body and culture: Beauty, ability, and growing up female. In V. Dhruvarajan, \& J. Vickers (Eds.), Gender, race, and nation: A global perspective (pp. 147-183). Toronto: University of Toronto Press.

Rice, C. (2003). Becoming women: Body image, identity, and difference in the passage to womanhood. Unpublished doctoral dissertation, York University, Toronto, Ont., Canada. 
Rice, C., \& Larkin, J. (2001, August). Mainstreaming body equity: Critical approaches to preventing body dissatisfaction and eating disorders in middle-school girls. Paper presented at the meeting of the American Psychological Association.

Rice, C., \& Russell, V. (1995). Embodying equity: Putting body and soul back into equity education. Our Schools/Ourselves, 7, 42-54.

Rice, C., \& Russell, V. (2002). Embodying equity: Body image as an equity issue. Toronto, Ont., Canada Green Dragon Press.

Rosenvinge, J., \& Gresko, R. (1997). Do we need a prevention model for eating disorders? Recent developments in the Norwegian school-based prevention model. Eating Disorders, 5, 110-118.

Rubin, L. R., Fitts, M. L., \& Becker, A. E. (2003). Whatever feels good in my soul": Body ethics and aesthetics among African American and Latina women. Culture, Medicine and Psychiatry, 27, 49-75.

Rumak, O. (Producer). (2001, January 31). Perfect breasts. [Television series episode]. The fifth estate. Toronto, Ont., Canada: Canadian Broadcasting Corporation.

Searles, R., Terry, D., \& Amos, R. (1986). Nutrition knowledge and body image satisfaction of female adolescents. Journal of Nutrition Education, 18, 123-127.

Shaw, H., Ramirez, L., Trost, A., Randall, P., \& Stice, E. (2004). Body image and eating disturbances across ethnic groups: More similarities than differences. Psychology of Addictive Behaviors, 18, 12-18.

Shroff, H., \& Thompson, J. K. (2004). Body image and eating disturbance in India: Media and interpersonal influences. International Journal of Eating Disorders, 35(2), 198- 203. 
Sibiya, N. (2000, July). Mainstreaming gender. Gender Matters: A Newsletter on Gender in South African Education, 4(1), 10.

Smolak, L. (1999). Elementary school curricula for the primary prevention of eating problems. In N. Piran, M. P. Levine, \& C. Steiner-Adair (Eds.), Preventing eating disorders: A handbook of interventions and special challenges (pp. 87-104). Philadelphia: Brunner/Mazel.

Smolak, L. (2004). Body image in children and adolescents: Where do we go from here? [Electronic version]. Body Image, 1, 15-28.

Smolak, L., \& Levine, M. P. (1996). Adolescent transitions and the development of eating problems. In L. Smolak, M. P. Levine, \& R. Striegel-Moore (Eds.), The developmental psychopathology of eating disorders: Implications for research, prevention, and treatment. (pp. 207-233). Mahwah, NJ: Lawrence Erlbaum Associates.

Thompson, B. (1992). "A way outa no way": Eating problems among African-American, Latina and White women. Gender and Society, 6, 546-561.

Thompson, B. (1994). A hunger so wide and so deep: American women speak out on eating problems. Minneapolis, MN: University of Minnesota Press.

van den Berg, P., Wertheim, E. H., Thompson, J. K., \& Paxton, S. J. (2002).

Development of body image, eating disturbance, and general psychological functioning in adolescent females: A replication using covariance structure modeling in an Australian sample. International Journal of Eating Disorders, 32, $46-51$. 
Vanderlinden, J., Vandereychen, W., van Dyck, R., \& Vertommen, H. (1993). Sexual abuse and body image distortion in the eating disorders. International Journal of Eating Disorders, 13, 187- 193.

Walcott, D. D., Pratt, H. D., \& Patel, D. R. (2003). Adolescents and eating disorders: Gender, racial, ethnic, sociocultural and socio-economic issues. Journal of Adolescent Research Special Issue: Eating Disorders in Adolescents, 18, 223 243.

Waller, G., Hamilton, K., Rose, N., Sumra, J., \& Baldwin, G. (1993). Sexual abuse and body image distortion in the eating disorders. British Journal of Clinical Psychology, 32, 350-352.

Wildes, J. E., \& Emery, R. E. (2001). The roles of ethnicity and culture in the development of eating disturbance and body dissatisfaction: A meta-analytic review. Clinical Psychology Review, 21, 521-551.

Wooley, S. (1994). Sexual abuse and eating disorders: The concealed debate. In P. Fallon, M. Katzman, \& S. Wooley (Eds.), Feminist perspectives on eating disorders (pp. 171-211). New York: Guilford Press.

Young-Hyman, D., Schlundt, D. G., Herman-Wenderoth, L., \& Bozylinski, K. (2003). Obesity, appearance, and psychosocial adaptation in young African American children. Journal of Pediatric Psychology, 28, 463-472. 